\title{
Development and Implementation of a Long-term Agricultural Systems Study: Challenges and Opportunities
}

\author{
J.P. Mueller, ${ }^{1}$ M. E. Barbercheck, ${ }^{2}$ M. Bell, ${ }^{3}$ C. Brownie, ${ }^{4}$ N.G. Creamer, ${ }^{5}$ A. Hitt, ${ }^{6}$ S. Hu, ${ }^{7}$ L. King, ${ }^{8}$ \\ H.M. Linker, ${ }^{9}$ F.J. Louws, ${ }^{10}$ S. Marlow, ${ }^{11}$ M. Marra, ${ }^{12}$ C.W. Raczkowski, ${ }^{13}$ D.J. Susko, ${ }^{14}$ and M.G. Wagger ${ }^{15}$
}

Additional IndeX words. soil quality, geographic information systems, interdisciplinary, largescale, research, agroecosystems, organic, sustainable agriculture

Summary. The Center for Environmental Farming Systems (CEFS) is dedicated to farming systems that are environmentally, economically, and socially sustainable. Established in 1994 at the North Carolina Department of Agriculture and Consumer Services (NCDACS) Cherry Farm near Goldsboro, N.C.; CEFS operations extend over a land area of about 800 ha (2000 acres) [ 400 ha (1000 acres) cleared]. This unique center is a partnership among North Carolina State University (NCSU), North Carolina Agriculture and Technical State University (NCATSU), NCDACS, nongovernmental organizations (NGOs), other state and federal agencies, farmers and citizens. Long-term approaches that integrate the broad range of factors involved in agricultural systems are the focus of the Farming Systems Research Unit. The goal is to provide the empirical framework to address landscape-scale issues that impact long-run sustainability of North Carolina's agriculture. To this end, data collection and analyses include soil parameters (biological, chemical, physical), pests and predators (weeds, insects and disease), crop factors (growth, yield, and quality), economic factors, and energy issues. Five systems are being compared: a successional ecosystem, a plantation forestry-woodlot, an integrated crop-animal production system, an organic production system, and a cash-grain [best management practice (BMP)] cropping system. An interdisciplinary team of scientists

The authors gratefully thank the United States Department of Agriculture (USDA) Southern Region Sustainable Agriculture Research and Education (SARE) Program for funding the initiation of this experiment, and the USDA National Research Initiative for funding several nested studies within this experiment. The authors also thank the College of Agriculture and Life Sciences at North Carolina State University, North Carolina Department of Agriculture and Consumer Services, North Carolina Agricultural and Technical State University State University, Rural Advancement Foundation International, Carolina Farm Stewardship Association, the No-Till Alliance, and other farmer groups and citizens for partnering in support of this long-term interdisciplinary research at CEFS. Finally, without the hard work and dedication of the CEFS superintendent Eddie Pitzer, assistant superintendent Jeff Chandler, and farm crew (Rodney Mozingo, Toby Grimes, Tim Matthews, and many others), technicians (Ken Fager, Brian Fouts, Robert Walters, Charles Warrick, Jr., Jim Driver) none of this work would be possible.

${ }^{1}$ Professor, Crop Science, Sustainable Agriculture Coordinator and Coordinator Farming Systems Research Unit.

${ }^{2}$ Associate professor of entomology.

${ }^{3}$ Research associate.

${ }^{4}$ Professor of statistics.

${ }^{5}$ Associate professor of horticultural science, director of the Center for Environmental Farming Systems; corresponding author.

${ }^{6}$ Farmer member of advisory board, Peregrine Farm, Inc., Graham, NC 27516

${ }^{7}$ Assistant professor of plant pathology.

${ }^{8}$ Professor emeritus of soil science.

${ }^{9}$ Professor of crop science and state IPM coordinator.

${ }^{10}$ Assistant professor of plant pathology.

${ }^{11}$ Advisory Board member, Rural Advancement Foundation International-USA, Pittsboro, NC 27312

${ }^{12}$ Professor of agricultural and resource economics.

${ }^{13}$ Associate professor, Department of Natural Resources, North Carolina Agricultural and Technical State University, Greensboro, NC 27420 .

${ }^{14}$ Former research associate for crop science, North Carolina State University. Currently, postdoctoral research fellow, Department of Plant Sciences, University of Western Ontario, London, ON, Canada, N6A 5B7.

${ }^{15}$ Professor of soil science, North Carolina State University, Raleigh, NC 27695. 
from the College of Agriculture and Life Sciences at NCSU and NCATSU, along with individuals from the NCDACS, NGO representatives, and farmers are collaborating in this endeavor. Experimental design and protocol are discussed, in addition to challenges and opportunities in designing and implementing longterm farming systems trials.

\section{W} Tithin the prevailing systems of agricultural production in the United States, agriculturists are working to understand the impact of current and new technologies on farmers, rural communities, and the environment. Agricultural systems lie at the intersection of economics, the social sciences, and biology (Spedding, 1996), yet the first two disciplines are often excluded when studying these systems. Even within the biological context, agricultural research is mostly disciplinary. Citizens of North Carolina and elsewhere are currently faced with landscapescale issues involving ground and surface water contamination, soil erosion, declining soil and water quality, loss of wildlife habitat, and declining rural communities. Longterm interdisciplinary systems research provides a unique opportunity to address these issues.

Spedding (1996) characterized systems as behaving as a whole in response to stimuli of any part. According to Ikerd (1993), whole systems possess synergistic qualities that are not contained in their individual components. Nevertheless, for purposes of experimentation, individual plants and fields are often considered the fundamental units for applied agricultural research. Farming systems, on the other hand, represent a different level of research focus in which fields are components of farms on which economic and sociological analyses can be performed (Loomis and Connor, 1994). Because of their complex nature and far-reaching implications, systems experiments tend to be designed for the long term. Southwood (1994) has reviewed the empirical value of such long-term experiments. Nevertheless, it may take many years for trends to emerge in complex systems. For instance, Poulton (1996) concluded that long-term experiments are essential in determining most soil-related factors affecting the sustainability of production. Systematic collections of information that characterize system performance will yield insight into critical performance parameters (and their interactions) which opens the possibility of predicting outcomes. This is critical for agriculture gripped in a continued recession where farm debt is increasing, about $35 \%$ of farms are in economic jeopardy and government payments constitute a substantial proportion of farm income (USDA, 2001). Noting the significant investment of tax dollars in agriculture, consumers are demanding that production systems address their concerns.

With some notable exceptions such as the Morrow Plots (Champaign, Ill.), Sanborn Field (Colombia, Mo.), the Jordan Plots (University Park, Pa.), and studies at Auburn University ( $\mathrm{Au}^{-}$ burn, Ala.), most long-term farming systems research projects have been initiated in the later half of the $20^{\text {th }}$ century. Yet even some of the most recent agricultural systems studies initiated during the past 10 to 15 years have begun to supply important information to guide future agricultural decisions. For example, conventional, low-input and organic farming systems are being compared in California with respect to pests, soil parameters, crop parameters and economic return (Temple el al., 1994). Initial results indicate the importance of active weed management and control of covercrop nitrogen supply for maintaining acceptable crop yields in low-input and organic systems.
In 1994 CEFS was established at a NCDACS facility near Goldsboro, N.C. CEFS research activities extend over an area of roughly 800 ha (400 ha of which are cleared) and are focused in four primary areas of research: 1) conservation tillage studies, 2) organic production, 3) farming systems research, and 4) animal production systems. Development of CEFS is a partnership among NCSU, NCATSU, NCDACS, other state and federal agencies, farmers, and citizens. CEFS is designated as a site to conduct longterm, large-scale systems experiments. Criteria for research to be conducted at CEFS include 1) farmers and other stakeholder groups are a part of the research planning process, 2) studies are interdisciplinary and systems-oriented, and 3) real-world problems are addressed on a farm-scale.

This project has been underway for 2 years, so only baseline data are currently available. Thus, rather than attempting to focus on results, this paper will focus on project initiation and management. Our aim is to describe opportunities, challenges, and lessons that can be learned in designing and implementing long-term interdisciplinary projects. This project seeks to identify methods that facilitate the design and analysis of largescale agricultural and ecological field studies (Scheiner and Gurvitch, 1993). Another goal is to provide information that leads to the establishment by USDA of a bioregional network of long-term agricultural research sites similar to the long-term ecological research network currently funded by the National Science Foundation. Such a network would allow for the coordinated, systematic and comprehensive study of agricultural sustainability on a national scale.

\section{Methods and materials}

Development of the Cefs

CONCEPT. In 1992, the directors of research and extension at NCSU formed a task force to review and document activities within the college that were focused on sustainable agriculture topics and to make recommendations regarding future program thrusts and needs. In 1993 the task force submitted a report to the directors titled Current Status and Future Direction of Sustainable Agriculture in the College of Agriculture and Life Sciences. The single most critical need 


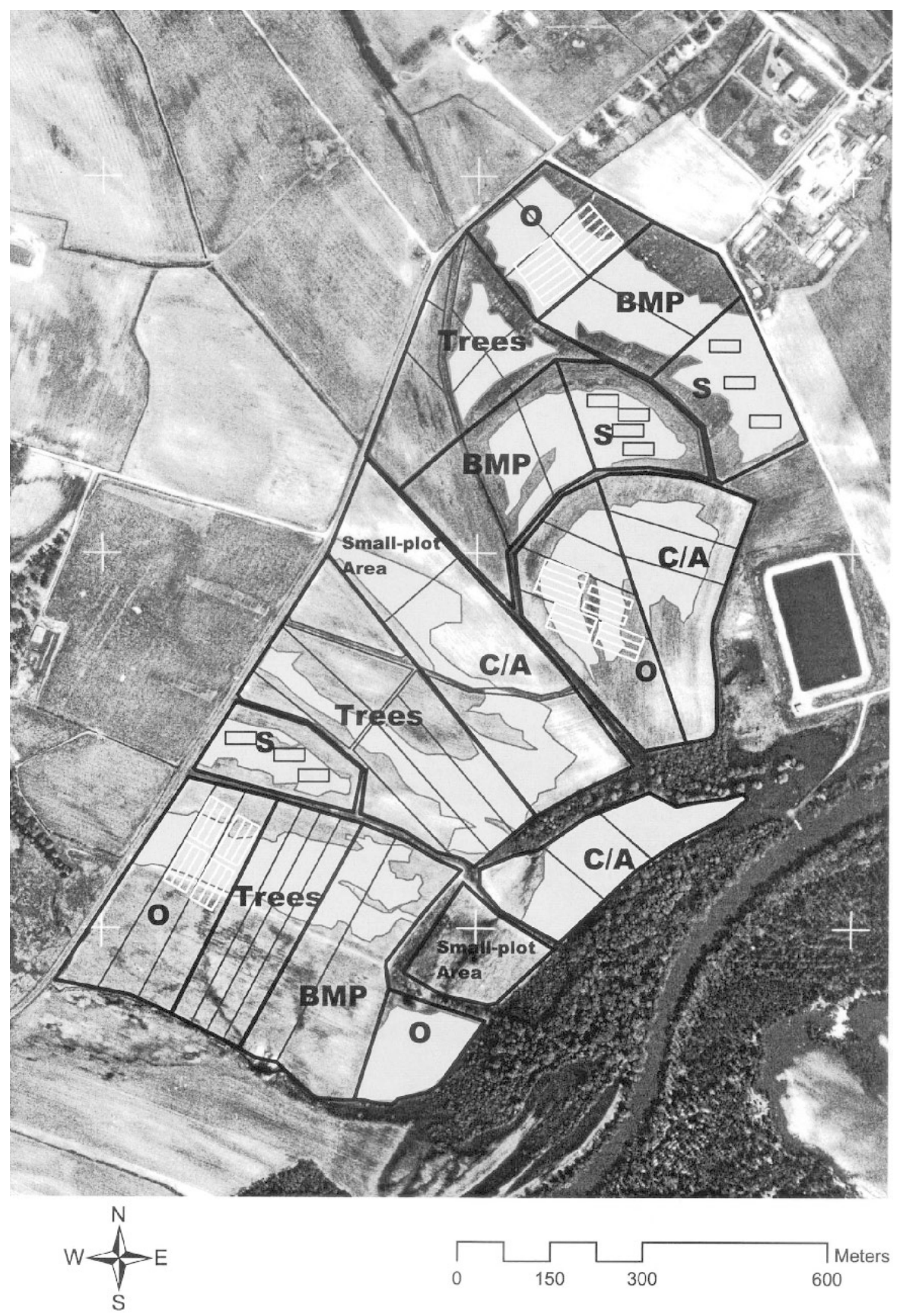

Fig. 1. Map of farming systems experiment, Goldsoboro, N.C., showing five systems: O (organic), BMP (best management practice), Trees (forestry system), C-A (integrated crop-animal system), $\mathbf{S}$ (successional ecosystem). Diagnostic soils are outlined in white. Small rectangles in the organic system represent the nested transition study. Small rectangles within the successional area represent sampling modules. Numbers refer to the subplots.

identified in the task force report was an "experiment station entirely devoted to the generation of scientific knowledge pertaining to sustainable agriculture issues." As a result of the task force report, in 1994, CEFS was established as the unique partnership previously described. The farming systems research group began meeting in agents; conventional, transitional, and organic farmers; individuals from many of North Carolina's agriculture-based, nonprofit organizations and farmer groups (Carolina Farm Stewardship Association, Rural Advancement Foundation International-USA, North Carolina Farm Bureau Federation, American Livestock Breeds Conservancy); personnel from the NCDACS; and staff from other state and federal agencies that are involved with agriculture. This 3-year group process consisted of regular meetings in which various models and concepts of systems research were presented and discussed. The project actually began as two separate studies. The first experiment was being developed for implementation on the organic unit at CEFS. That trial was to compare several different long-term organic farming management strategies (for example, with or without the integration of animals). At the same time, the systems experiment described in this paper was also being developed, but without an organic component. In March 1997, a workshop facilitated by Bill Liebhart (former director, University of California Sustainable Agriculture Research and Educaton Program, Davis) and Benjamin Stinner (endowed chair, Agroecosystems Management Program, The Ohio State University, Wooster) was held to address the key issues involved in system design and implementation. As a result, faculty arrived at a consensus opinion that there were significant benefits in combining the two experiments and working together in this effort. That decision increased the breadth and depth of the experiment and resulted in the drafting of a research proposal. The proposal was submitted in 1997 to USDA Southern Region sustainable agriculture research and education (SARE) program to fund the initiation of the study.

Experimental design, plot IDENTIFICATION, AND ARRANGEMENT. This large experiment is unique in the USDA Southern Region. About 81 ha (200 acres) were divided, based on intensive soil mapping, into three replications of five systems: three agriculture production systems, a successional ecosystem, and a plantation forestry system. Individual subplots varied in size from about 1.2 to 3.6 ha ( 3 to 9 acres) depending on the system and the replicate. Soils were intensively 
Table 1. Three-year rotation subplots for best management practicessystem, Farming Systems Research Unit, Center for Environmental Framing Systems, Goldsboro, N.C.

\begin{tabular}{lcc}
\hline & \multicolumn{2}{c}{ Subplot(tillage system) } \\
\cline { 2 - 3 } Year & Conventional & Notillage \\
\hline 1 & Cotton & Cotton \\
2 & Corn & Corn \\
3 & Peanut & Peanut
\end{tabular}

mapped in 1996 based on soil type and drainage. Blocks were designated based on similar diagnostic soil types assigned within each block of five systems. Diagnostic soil series within the three blocks included Tarboro loamy sand (block A) and Wickham sandy loam and State loam (blocks B and C). All intensive sampling and measurements are made within these diagnostic soil units (Fig. 1). Five, permanent, georeferenced sampling points were designated within the diagnostic soil of each subplot in each block and system. These points were selected through a random numbers table representing number of meters perpendicular to transect(s) located in the diagnostic soil portion of each subplot. Soil sampling is coordinated between researchers allowing us to gain information of the effects of systems on the interaction among physical, chemical, and biotic components and on the spatial and temporal variation of their interactions. About 30 to 40 soil cores are taken at each sampling point and then divided among individual researchers for specific analyses (see below).

EXPERIMENTAL SYSTEMS. Each system is characterized by its own management challenges. Specifically, systems under comparison include the following:

Conventional cash cropping system (BMPs, short-rotation cash-crop). This system represents a standard for comparison. It is representative of one of the predominant farming systems in eastern North Carolina and other southern states. It is characterized by management practices commonly used by growers: annual crops, short rotations, and absence of animals. The crops are scouted for pests on a regular basis and pesticides used only when economically justified. The system is represented by conventional till and no-till suplots and a 3-year rotation (Table 1 ).
Integrated crop-animal system (biologically diverse agroecosystem). Farming systems may benefit from synergies provided by the wise integration of crops and livestock. Perennial species and long crop rotations support a biologically diverse farming system. One feature of this system is the inclusion of cover and pasture crops for every field in the rotation. Another feature is a relatively low-cost fencing and drinking water system for livestock to ensure that plant nutrients are efficiently recycled through the grazing animal. The system has three subplots representing three entry points of a 15-year rotation (Table 2). Pasture species selected according to soil adaptation are warm-season perennial grasses [switchgrass (Panicum virgatum), eastern gamagrass (Tripsacum dactyloides), indiangrass (Sorghastrum nutans), and big bluestem (Andropogongerardi)] and cool-season annuals [rye (Secale cereale) and ryegrass (Lolium multiflorum)]. The pastures were initially stocked with dairy steers (Bos taurus) followed by beef heifers (Bostaurus). In the future, the possibility exists to incorporate small ruminants such as meat goats (Capra hircus), or monogastrics such as swine (Sus scrofa domesticus) or poultry (Gallus spp.). The development of an agroforestry component will be part of this system and will exploit field and pasture boundaries to produce forest products coincident with agricultural crops and livestock.

Organic production system. Organic production systems employ unique approaches to nutrient availability, pest control and soil management. These approaches are profoundly different from predominant conventional agricultural production systems. Furthermore, there is a scarcity of information with respect to the longterm effects of such systems. Currently, the focus of this system is to evaluate various strategies of transition from conventional to organic production systems within the context of the overall experiment. The initial 3-year transition rotation under study includes: rye cover-soybean (Glycine max)-hairy vetch (Vicia villosa) and rye coversweetpotato (Ipomoea batatas) wheat (Triticum aestipum)-cabbage (Brassica oleracea var. capitata) (Table 3). Nested within two of the four subplots of this system are two starts of a sixtreatment experiment designed to focus on transition strategies. The next phase of this treatment will be to build a long-term rotation cycle. Long-term management strategies will be selected for comparative purposes, with at least one that includes animals.

Plantation forestry-woodlot (commercially valuable forest species). Forest species are an important component of the southern U.S. landscape. Forestry is a thriving commercial enterprise, common to most farms in the region. Forestry systems sequester nutrients and energy in long-term perennial cycles and offer the possibility for intriguing comparisons with other farming systems. This system seeks to maintain the identity of the woodlot as an ecosystem while employing appropriate silvicultural practices. Species included in the experiment include: cherrybark oak (Quercus falcata var. padgodefolia), bald cypress (Taxodium distichum), green ash (Fraxinus pennsylvanica var. lanceolata), and longleaf pine (Pinus palustris). The inclusion of several species allows for comparisons of multiple rotation lengths and silvicultural systems (clearcut, shelterwood, strip and selection systems).

Successional ecosystem (oldfield succession). This represents one of the important standards (controls) for the comparison of environmental impacts

Table 2. Fifteen-year rotation subplots of integrated crop-livestock system, Farming Systems Research Unit, Center for Environmental Farming Systems, Goldsboro, N.C.

\begin{tabular}{llll}
\hline & & Subplot & \\
\cline { 2 - 4 } Year & Field A & Field B & Field C \\
\hline Year 1 & Pasture $^{\mathrm{z}}$ & Peanut (p) & Cotton \\
Year 2 & Pasture & Cotton (ct) & Corn \\
Year 3 & Pasture & Corn (c) & Wheat-soybean \\
Year 4 & Pasture & Wheat-soybean (ws) & Sweetpotato \\
Year 5 & Pasture & Sweetpotato (sp) & Peanut \\
Year 6-10 & p-ct-c-ws-sp & Pasture & ct-c-ws-sp-p \\
Year 11-15 & p-ct-c-ws-sp & p-ct-c-ws-sp & Pasture \\
\hline
\end{tabular}

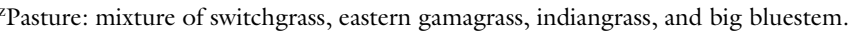


Table 3. Transitional phase subplots for organic farming system, Farming Systems Research Unit, Center for Environmental Framing Systems, Goldsboro, N.C.

\begin{tabular}{|c|c|c|c|c|}
\hline \multirow[b]{2}{*}{ Year } & \multicolumn{4}{|c|}{ Subplot } \\
\hline & 1 & 2 & 3 & 4 \\
\hline 1 & Soybean & Corn & Corn & Corn \\
\hline 2 & Sweetpotato & Soybean ${ }^{\mathrm{z}}$ & Corn & Corn \\
\hline 3 & Wheat-cabbage & Sweetpotato & Soybean $^{\mathrm{x}}$ & Corn \\
\hline 4 & Corn & Wheat-cabbage & Sweetpotato & Soybean \\
\hline 5 & Soybean & Corn $^{y}$ & Wheat-cabbage & Sweetpotato \\
\hline 6 & Sweetpotato & Soybean & Corn $^{w}$ & Wheat-cabbage \\
\hline
\end{tabular}

${ }^{{ }^{z}}$ Start $1^{\text {st }}$ cycle of nested transition study.

yEnd first cycle of nested transition study

${ }^{x}$ Start $2^{\text {nd }}$ cycle of nested transition study.

${ }^{\mathrm{w}}$ End $2^{\text {nd }}$ cycle of nested transition study.

offarming. Agricultural fields are maintained for high productivity as plant communities that are prevented from a successional return to natural vegetation. The opportunity to study in detail the processes and biological dynamics that take place when land is released from agriculture may be useful in understanding the complex interactions involved in agricultural sustainability. Areas selected for this system have been allowed to succeed naturally, influenced only by natural processes. Three 1,000- $\mathrm{m}^{2}(10,764$ $\mathrm{ft}^{2}$ ) sampling modules have been located within each replication of the successional ecosystem where intensive measurements (e.g., plant composition, densities, and population dynamics) are taking place. In addition to studying the direct effects of succession on agricultural land, the edge or border effects of successional areas where they contact agricultural land and forests may provide further insight to the interplay and importance of differing habitats on the ecology of pests and beneficial organisms.

Data collection and the nestING OF SECONDARY EXPERIMENTS. We anticipate that the systems will begin to diverge based on management strategy during the first 3 to 5 years. In that time, we will monitor soil physical (bulk density, aggregate stability, soil water characteristics, pore size distribution, hydraulic conductivity) chemical $(\mathrm{pH}$, infiltration, organic matter, inorganic and total nitrogen), and biological properties [carbon dioxide $\left(\mathrm{CO}_{2}\right)$ evolution and microbial biomass, bacteria, and nematodes), weed populations (species and distribution), diseases (including disease-suppressive soils), insects (beneficials and pests), plant growth, development, biomass, and yield. Because the same crops aren't represented in each system every year, certain measurements are eliminated whereas others can be emphasized.

Ecological-biological shifts. Given the diversity in the systems under study, dynamic and subtle shifts are anticipated in micro- and macro-fauna, weed species, disease and insect pressure, and indigenous plant species.

Soil quality-natural resource indices. Long- and short-term assessment of changes in dynamic soil characteristics.

Water quality. Agriculture's impact on water quality is of key concern in the Neuse River basin. The Neuse River and Little River surround the CEFS facility. Test wells already in place are evaluating the role of riparian buffers in reducing surface and subsurface runoff of nutrients from crop fields and pasture. Further water quality evaluations are proposed for the systems experiment.

Economic performance evaluations. Field-level data collected from CEFS on inputs (including management) and outputs will be used to compare the other systems to the conventional cash cropping system. The method used will be partial budgeting (M.C. Marra, unpublished), which is a commonly used analytical tool for economic comparisons of this type. This method will measure the profitability of each system relative to the convenGoldsboro, N.C. ${ }^{\mathrm{z}}$ second year, only rescue chemical treatments will be applied). tional cash cropping system (the system assumed to be used widely at present). In addition to partial budgeting analysis, future plans are to include measuring off-site costs, benefits, and community impacts. The method of benefits transfer will be used to place a value on the environmental quality changes to include them in economic results. Community impacts will be assessed using community multipliers appropriate for the area.

While this experiment was designed to investigate issues of agricultural systems sustainability in the longterm, we recognize the importance of answering short-term questions as the study progresses. As such, our interdisciplinary team also focuses on nesting other experiments within the context of this larger systems experiment. For example, as we transition from conventional to organic in the organic treatment, we have nested a USDA National Research Initiative (NRI)funded study to evaluate six strategies, from a biological and economic perspective, of making the transition.

In the transition from conventional to organic production systems there is often a period of lowered yields followed by return to yields similar to conventional production (Brusko, 1989; Liebhardt et al., 1989; MacRae et al., 1993). This transition effect has been attributed in part to changes in soil biological, chemical, and physical properties governing nutrient cycling, plant growth and development (Pfiffner and Niggli, 1996; Wander et al., 1994). These changes have been documented (e.g., Hanson et al., 1997; Lanini et al., 1994; Scow et al., 1994), but strategies to minimize their negative economic impacts have been elusive. Five strategies of transition are being evaluated and compared to a conventional control: 1) conventional

Table4. Treatment plan for nested transitional experiment within the organic system, Farming Systems Research Unit, Center for Environmental Farming Systems,

\begin{tabular}{llll}
\hline Plot-treatment & Year 1 & Year2 & Year3 \\
\hline 1) Conventional & $(+\mathrm{F}+\mathrm{H}+\mathrm{I})$ & $(+\mathrm{F}+\mathrm{H}+\mathrm{I})$ & $(+\mathrm{F}+\mathrm{H}+\mathrm{I})$ \\
2) Organic & $(-\mathrm{F}-\mathrm{H}-\mathrm{I})$ & $(-\mathrm{F}-\mathrm{H}-\mathrm{I})$ & $(-\mathrm{F}-\mathrm{H}-\mathrm{I})$ \\
3) Progressive & $(-\mathrm{F}+\mathrm{H}+\mathrm{I})$ & $(-\mathrm{F}+\mathrm{H}+\mathrm{I})$ & $(-\mathrm{F}-\mathrm{H}-\mathrm{I})$ \\
4) Progressive & $(+\mathrm{F}-\mathrm{H}+\mathrm{I})$ & $(+\mathrm{F}-\mathrm{H}+\mathrm{I})$ & $(-\mathrm{F}-\mathrm{H}-\mathrm{I})$ \\
5) Progressive & $(+\mathrm{F}+\mathrm{H}-\mathrm{I})$ & $(+\mathrm{F}+\mathrm{H}-\mathrm{I})$ & $(-\mathrm{F}-\mathrm{H}-\mathrm{I})$ \\
6) Progressive & $(\mathrm{GR})$ & $(\mathrm{GR})$ & $(-\mathrm{F}-\mathrm{H}-\mathrm{I})$
\end{tabular}

${ }^{\mathrm{z}}$ Notation used for treatment identification: [synthetic $\mathrm{F}$ (fertilizer), $\mathrm{H}$ (herbicide), I (insecticide and fungicide)] - (without), + (with). GR (gradual reduction of all synthetic inputs, for example, banding vs. broadcasting. In the 
production inputs (positive control), 2 ) immediate withdrawal of conventional inputs and substitution by organic management practices and inputs, 3), 4), and 5) sequential withdrawal of one of the major classes of inputs (fertilizer, herbicide, insecticides, and fungicides) in the first 2 years, followed by a third year where all classes of synthetic inputs have been replaced in an organic system (three treatments ); and 6) gradual withdrawal of all classes of inputs over the 3 -year period until an organic system is in place by the third year. Treatments 3,4 , and 5 are included to evaluate the impact of various classes of inputs on the system. The transition is being studied in the following 3-year crop rotation: soybeans, sweetpotatoes, and wheat-cabbage. The rotation was selected as one that was logical for a conventional grower who was transitioning to organic based on ease production. Various edaphic and biotic parameters being measured in this study include aboveground biomass of cover crop and cash crop, nutrientenergy flows, soil quality indices (physical, chemical, biological), decomposition rates, soil microbiological properties, insects, weeds, disease, crop yield and quality; soil microarthropods, soil entomopathogens, and economics.

\section{Discussion}

As previously described, planning for the experiment began more than 3 years before the first grant application was initiated. Some grew impatient during the planning process, and declined to participate further because of slow progress. Nonetheless, the lengthy planning process was of significance to those that remained, especially in retrospect. Project planning is often limited and directed by funding opportunities and granting cycles. In this case, faculty came to the table and became vested in the process and design without promises of funds or future support. On the other hand, while careful planning is critical to any experiment, no amount of preplanning can completely prepare a group for the scope of issues that arise during implementation of a project like the one described here. Issues often develop that need careful debate and quick decision making. Unfortunately, many issues do not have one right answer. Typically, tradeoffs involve rectifying short-term and long-term project goals.
One of the first controversial issues debated by the group was whether to include every crop in the rotation each year, the preferred approach in rotation experiments because it accounts for seasonal variability. In an experiment where large plot size is important to the integrity of the experiment and the sampling scheme is intense, including every crop each year can be prohibitive. For example, in this experiment, including all crops each year would require 114 plots. In such a scheme, plot size would be significantly reduced and the ability for intensive sampling lost. What we lost by not including all crops each year is offset by maintaining plot size and intensive sampling. Yet, we felt it important to make two exceptions and replicate in time at least partially. In the integrated crop-animal system, because it has a very long rotation ( 15 years), three subplots have been initiated that represent three starting points in the rotation (Table 1 ). This also allows for periodic nested comparisons with the BMP treatment because the crop-animal system matches the BMP system in 6 of 9 years. Also, in the organic system we are initially seeking short-term results and have accounted for seasonal variation by initiating the nested transition experiment in 1999 and 2000. Therefore, the rotational sequence, which is critical to the transition to the organic system, is left intact and seasonal variation can be tested.

Handling treatment protocols across replications is another difficult issue. The question arises, does each treatment necessarily receive the same input in all replications? For example, if a BMP treatment in one replication has a late-season weed outbreak that should (based on scouting criteria) receive an herbicide input, do the other two replications (with no weeds present) receive the same herbicide input? While we are still debating this issue, one thing is for certain, faculty feel very strongly on one side of this issue or the other.

Constructing the management philosophy that will guide the BMP system has also been a challenge; our central question is whether the BMP system should reflect current and future common agricultural practices, or whether the system should reflect university recommendations.

Including a statistician (Cavell
Brownie) and a Global Positioning System (GPS)-Geographic Information Systems (GIS) expert (Larry King) on the research team from the beginning has been crucial to this project. Being able to monitor and map soil variability, sampling points, plot borders, etc. through time will remain essential. For example, in 1999 Hurricane Floyd caused flooding along the Neuse River and many of the plots were under significant amounts of standing river water. Because we had collected and archived soil from georeferenced sampling points throughout the area, we were able to return to the exact sampling points and collect new soil samples in order to determine the impact of the flood on a range of soil characteristics. Moreover, Brownie has also help us move forward through otherwise significant stumbling blocks. With few models available to aid discussion of experimental design and sampling protocol, successfully resolving statistical questions was a key part of decision making. Long-term data management is also critical to the success of this project and the coordinated effort between the GIS manager and statistician have achieved results that are well beyond the capabilities of any individual discipline-oriented faculty member.

Team building. It is important for a project like the one described here to have an effective team with a sense of ownership of the project. Meetings are held often, and decisions are made by consensus even when divergent opinions and arguments are evident at the outset. A sense of cooperation and support has been developed such that resource sharing and authorship issues have not been problematic. This interdisciplinary effort has been supported by the administration and department heads of the College of Agriculture and Life Sciences at NCSU. Several of faculty members involved are (or were) at the assistant professor level; they, too, have felt that their involvement in the project is supported by their departments. To be successful, long-term interdisciplinary projects need to have short-term objectives and results in support of the long-term goals. Universities and departments will need to value interdisciplinary cooperation and develop innovative ways to share resources, graduate students, and credit across departmental lines. 
We contend that the sustainability of agriculture in the U.S. will depend in part, on interdisciplinary interaction and cooperation and long-term experimentation. It is no longer prudent to ignore the interactions among agroecosystem components, especially as efforts continue to make production systems more sustainable from economic, environmental, and social perspectives. Long-term, large-scale, systems experiments are important to these efforts but are rare due to the significant resources required including the start-up costs and scientist hours. However, the need for information generated by permanent, broad-based studies is clear. As such, we encourage USDA to consider structuring a new program that would support and network long-term agricultural research sites that represent different areas and bioregions of the country.

\section{Literature cited}

Brusko, M. 1989. What really happens when you cut chemicals. New Farm (MayJune):19.

Hanson, J.C., E. Lichtenberg, and S.E. Peters. 1997. Organic versus conventional grain production in the mid-Atlantic: An economic and farming system overview. Amer. J. Alt. Agr. 12:2-9.

Ikerd, J. E. 1993. The need for a systems approach to sustainable agriculture. Agr. Ecosyst. Environ. 46:147-160.

Lanini, W.T., F. Zalom, J. Marois, and H. Ferris. 1994. Researchers find short-term insect problems, long-term weed problems. Calif. Agr. 48:27-33.

Liebhardt, W.C., R.W. Andrews, M.N. Culik, R.R. Harwood, R.R. Janke, J.K. Radke, and S.L. Rieger-Schwartz. 1989. Crop production during conversion from conventional tolow-input methods. Agron. J. 81:150-159.

Loomis, R.S. and D.J. Connor. 1994. Crop ecology. Cambridge Univ. Press, Melbourne, Australia.

MacRae, R.J., S.B. Hill, G.R. Mehuys, and J. Henning. 1993. Farm-scale agronomic and economic conversion from conventional to sustainable agriculture. Adv. Agron. 43:155-198.

Pfiffner, L. and U. Niggli. 1996. Effects of bio-dynamic, organic and conventional farming on ground beetles and other epigaeic arthropods in winter wheat. Biol. Agr. Hort. 12:353-364,

Poulton, P.R. 1996. The Rothamsted longterm experiments: Are they still relevant? Can. J. Plant Sci. 76: 559-571.
Scheiner, S.M. and J. Gurvitch. 1993. Design and analysis of ecological experiments. Chapman Hall, New York.

Scow, K.M., O. Somasco, N. Gunapala, S. Lau, R. Venette, H. Ferris, R. Miller, and C. Shennan. 1994. Transition from conventional to low-input agriculture changes soil fertility and biology. Calif. Agr. 48:2026.

Southwood, T.R.E. 1994. The importance of long-term experimentation, p. 3-8. In: R.A. Leigh and A.E. Johnson (eds.). Longterm experiments in agricultural and ecological sciences. CAB Intl., Wallingford, U.K.

Spedding, C.R.W. 1996. Agriculture and the citizen. Chapman Hall, New York.

Temple, S.R., O.A. Somasco, M. Kirk, and D. Friedman. 1994. Conventional, lowinput and organic farming systems compared. Calif. Agr. 48:14-19.

U.S. Department of Agriculture. 2001. Farm income and costs, farm balance sheetassets, farm balance sheet-debts. USDA Econ. Res. Serv. 1 July 2001. <http:// www.ers.usda.gov/Briefing/Farm/Income $/>$.

Wander, M.M., S.J. Traina, B.R.. Stinner, and S.E. Peters. 1994. Organic and conventional management effects on biologically active soil organic matter pools. Soil Sci. Soc. Amer. J. 58:1130-1139. 